\title{
Validation of a method to assess emphysema severity by spirometry in the COPDGene study
}

\author{
Mariaelena Occhipinti ${ }^{1,2^{*}+}$ D, Matteo Paoletti ${ }^{1 \dagger}$, James D. Crapo ${ }^{3}$, Barry J. Make ${ }^{3}$, David A. Lynch ${ }^{4}$, Vito Brusasco ${ }^{5}$,
} Federico Lavorini ${ }^{1}$, Edwin K. Silverman ${ }^{6}$, Elizabeth A. Regan ${ }^{3 \dagger}$ and Massimo Pistolesi ${ }^{1+}$

\begin{abstract}
Background: Standard spirometry cannot identify the predominant mechanism underlying airflow obstruction in COPD, namely emphysema or airway disease. We aimed at validating a previously developed methodology to detect emphysema by mathematical analysis of the maximal expiratory flow-volume (MEFV) curve in standard spirometry.

Methods: From the COPDGene population we selected those 5930 subjects with MEFV curve and inspiratoryexpiratory $\mathrm{CT}$ obtained on the same day. The MEFV curve descending limb was fit real-time using forced vital capacity (FVC), peak expiratory flow, and forced expiratory flows at 25, 50 and 75\% of FVC to derive an emphysema severity index (ESI), expressed as a continuous positive numeric parameter ranging from 0 to 10. According to inspiratory CT percent lung attenuation area below - $950 \mathrm{HU}$ we defined three emphysema severity subgroups (\%LAA-950insp $<6,6-14, \geq 14$ ). By co-registration of inspiratory-expiratory CT we quantified persistent (\%pLDA) and functional (\%fLDA) low-density areas as CT metrics of emphysema and airway disease, respectively.

Results: ESI differentiated CT emphysema severity subgroups increasing in parallel with GOLD stages $(p<.001)$, but with high variability within each stage. ESI had significantly higher correlations $(p<.001)$ with emphysema than with airway disease $C T$ metrics, explaining $67 \%$ of \%pLDA variability. Conversely, standard spirometric variables $\left(\mathrm{FEV}_{1}, \mathrm{FEV}_{1} / \mathrm{FVC}\right.$ ) had significantly lower correlations than ESI with emphysema CT metrics and did not differentiate between emphysema and airways $C T$ metrics.
\end{abstract}

(Continued on next page)

\footnotetext{
*Correspondence: mariaelena.occhipinti@unifi.it;

mariaelena.occhipinti@gmail.com

Mariaelena Occhipinti and Matteo Paoletti these authors share first name authorship

${ }^{\dagger}$ Elizabeth A. Regan and Massimo Pistolesi these authors share senior authorship

${ }^{1}$ Section of Respiratory Medicine, Department of Experimental and Clinical Medicine, University of Florence, Largo A. Brambilla 3, 50134 Florence, Italy ${ }^{2}$ Section of Radiology, Department of Biomedical, Experimental, and Clinical Sciences, University of Florence, Largo A. Brambilla 3, 50134 Florence, Italy Full list of author information is available at the end of the article
} 
(Continued from previous page)

Conclusions: ESI adds to standard spirometry the power to discriminate whether emphysema is the predominant mechanism of airway obstruction. ESI methodology has been validated in the large multiethnic population of smokers of the COPDGene study and therefore it could be applied for clinical and research purposes in the general population of smokers, using a readily available online website.

Keywords: Spirometry, Emphysema, Airway obstruction, Computed tomography, Vital capacity

\section{Background}

Expiratory airflow obstruction as detected by spirometry is the hallmark of chronic obstructive pulmonary disease (COPD). In each patient the relative contribution of conductive airways narrowing and emphysematous parenchymal destruction determines the complexity and heterogeneity of the clinical presentation in COPD [1-4]. Emphysema is a major determinant of lung function decline and all-cause mortality in patients with COPD $[5,6]$. Lung volumes and diffusing capacity are traditionally used to infer the presence and the severity of emphysema. However, these measurements are not always available in clinical practice, not usually included among the variables to enroll patients in large clinical and pharmacologic trials, and considered not to be essential to patient management by the 2019 Report of the Global Initiative for Chronic Obstructive Lung Disease (https://goldcopd.org/).

Recently the application of computed tomography (CT) to the study of COPD has provided information on the pathological changes occurring in the disease [7, 8]. Bronchial wall thickening, gas trapping, and parenchymal destruction are qualitatively evaluated and quantitatively assessed by dedicated software [9-12]. Identification of the prevailing mechanism for expiratory airflow obstruction, i.e. airways disease vs. parenchymal destruction, can be obtained by CT analyses, such as parametric response maps from co-registration of inspiratory and expiratory scans [13] and disease probability measure maps [14]. Quantitative evaluation of CT scans has been introduced in large-scale COPD population studies $[15,16]$. However, the high prevalence of COPD in the general population [17], the relative limited availability of CT and its intrinsic use of ionizing radiation limit the use of CT imaging for the diagnosis and treatment of COPD in clinical routine as well as in large-scale clinical, epidemiologic, and pharmacologic trials. Furthermore, CT metrics do offer a quantitative evaluation of the extent of lung pathology but no information on the mechanism of airflow limitation.

A model based on the mathematical fitting of the descending limb of the maximal expiratory flow-volume curve (MEFV) in standard spirometry can provide a functional emphysema severity index (ESI) that strongly correlates with the extent of emphysema on CT-based radiomics, as demonstrated in a previous study conducted in a small cohort of Caucasian patients with COPD [18].

The aim of the present study was to validate by CT metrics the ESI methodology for the assessment of emphysema severity by standard spirometry in the large multiethnic population of US subjects enrolled in the COPDGene study, in order to demonstrate the generalizability of the method for pharmacologic trials and its utility in clinical care of former and current smokers.

\section{Methods}

COPDGene is a multicenter study designed to identify genetic factors, to characterize CT subtypes, and determinants of progression. Study details have been previously published [16]. Institutional review boards approved the study across the 21 US participating Clinical Centers between January 2008 and June 2011 and all participants provided written informed consent. COPDGene included current and former smokers aged 45-80 years, either non-Hispanic whites or non-Hispanic African Americans. The study included smoker controls (GOLD 0), GOLD 1-4 and PRISm (Preserved Ratio Impaired Spirometry, i.e. $\mathrm{FEV}_{1} / \mathrm{FVC} \geq 0.7$ and postbronchodilator $\mathrm{FEV}_{1}<80 \%$ of predicted) subjects for a total of 10,371 subjects with at least 10 pack-years smoking history [16]. All participants underwent spirometry and inspiratory-expiratory CT.

\section{Spirometry}

All subjects underwent pre- and post- bronchodilator spirometry using the NDD EasyOne Spirometer (Zurich, Switzerland) according to the American Thoracic Society criteria [19]. Pre-bronchodilator spirometry was followed by administration of two puffs of albuterol HFA using appropriate spacers such as Aerochamber ${ }^{\circ}$ (Monaghan Medical Corporation, Plattsburgh, NY). Post-bronchodilator spirometry was performed 15-20 min post albuterol administration.

\section{Quantitative CT analysis}

Quantitative CT analysis was performed by VIDA (Coralville, IA) [20] and Imbio LLC (Minneapolis, MN) software programs [13]. VIDA was used to assess the 
percent of low attenuation area below $-950 \mathrm{HU}$ at full inspiration (\% LAA $_{-950 i n s p}$ ), below $-856 \mathrm{HU}$ at end-tidal expiration (\% $\left.\mathrm{LAA}_{-856 \mathrm{exp}}\right)$, and the average wall thickness of bronchi with $10 \mathrm{~mm}$ internal perimeter (AWTPi10). Imbio was used to derive persistent low-density areas (\%pLDA) and functional low-density areas (\%fLDA) from co-registered inspiratory-expiratory CT scans representing regions of emphysematous and nonemphysematous gas-trapping, respectively.

\section{Emphysema severity index (ESI)}

The ESI software is designed to perform a fast fitting to the descending limb of the MEFV curve suitable for real-time analysis in clinical practice and for large dataset in clinical and pharmacologic trials (freely available for research at url: https://www.emphysema.app). The ESI online app ultimately provides a continuous positive numeric parameter ranging from 0 to 10 after receiving discrete input parameters (PEF, FEF25, FEF50, FEF75, FVC) derived from the MEFV curve obtained at spirometry. The procedure is fully automated and the results are calculated real -time. For theoretical background of ESI see reference [18].

\section{Data analysis}

Association between ESI, $\mathrm{FEV}_{1}, \mathrm{FEV}_{1} / \mathrm{FVC}$ and CT metrics was assessed by Pearson's $r$ correlation and $\mathrm{R}^{2}$ determination coefficients. Robust Steiger's Z-test was used to assess statistical significance of the difference between correlations [21]. Multiple regression analysis was performed using ESI as dependent variable and \%pLDA and \%fLDA as independent variables to further evaluate the association profile between the three parameters. Subjects were allocated in subgroups based on the \%LAA-950insp cut-off reported by the Fleischner Society for the presence and the severity of emphysema: no emphysema (NE, \%LAA_950insp <6), moderate emphysema (ME, $6 \leq \%$ LAA-950insp $_{14}$ 14), and severe emphysema (SE, \%LAA-950insp $_{2} 14$ ) [7, 22]. Differences in ESI among GOLD stages and CT emphysema severity subgroups were assessed by one-way ANOVA and Welch's $t$-test. The distribution of CT subgroups (NE, ME, SE) within the ESI value range from 0 to 10 was evaluated by contingency table. Goodman and Kruskal's gamma test was performed to assess the strength of the association between the different ranges of ESI and emphysema CT metrics.

All analyses were performed using SPSS (PCWIN 11.5.1, Chicago, IL, USA) and Orange software [23]. Two-sided alpha 0.05 was considered significant.

\section{Results}

From the 10,371 subjects enrolled in the COPDGene study we excluded those with MEFV curves not satisfying the standard quality criteria $(n=1397)$ or the automated quality check by ESI program $(n=71)$, those with spirometry and CT obtained in a different day $(n=1673)$, those who had spirometry but no CT $(n=276)$, those who had CT analyzed by VIDA software only $(n=945)$, and never smokers $(n=79)$. ESI was calculated in 5930 smokers distributed across all GOLD stages (GOLD 0, $n=2446$; GOLD 1, $n=499$; GOLD 2, $n=1169$; GOLD 3, $n=662$; GOLD $4, n=313)$ and PRISm $(n=641)$. Table 1 describes the anthropometric, pulmonary function and CT metrics data of the final population.

The correlation and the determination coefficients between functional parameters and CT metrics are reported in Table 2. ESI had stronger correlations with emphysema CT metrics (\%LAA-950insp, \%pLDA) than standard functional parameters of airflow obstruction $\left(\mathrm{FEV}_{1}, \mathrm{FEV}_{1} / \mathrm{FVC}\right)$. ESI had weaker correlations with airway disease (AWTPi10, \%fLDA) than with emphysema CT metrics (\%LAA-950insp, \%pLDA). Considering coefficients of determination $\left(\mathrm{R}^{2}\right)$, ESI accounted for $35 \%$ of

Table 1 Anthropometric, pulmonary function and CT metrics data of the 5930 subjects of the COPDGene population included in the study

\begin{tabular}{|c|c|}
\hline $\begin{array}{l}\text { Men/Women } \\
\text { Non-Hispanic Whites/African Americans }\end{array}$ & $\begin{array}{l}3128 / 2802 \\
4389 / 1541\end{array}$ \\
\hline PRISm/GOLD0/GOLD1-4 & $641 / 2646 / 2643$ \\
\hline Age (yr) & $60.1(8.9)$ \\
\hline BMI $\left(\mathrm{kg} / \mathrm{m}^{2}\right)$ & $28.8(6.2)$ \\
\hline Smoking history (pack/years) & $44.2(24.6)$ \\
\hline $\mathrm{FEV}_{1}$ (\%pred) & $77.4(25.0)$ \\
\hline FVC (\%pred) & $87.9(17.8)$ \\
\hline $\mathrm{FEV}_{1} / \mathrm{FVC}$ & $0.66(0.16)$ \\
\hline PEF (L/s) & $6.4(2.4)$ \\
\hline FEF25\% (L/S) & $4.8(2.6)$ \\
\hline FEF50\% (L/s) & $2.5(1.7)$ \\
\hline FEF75\% (L/s) & $0.6(0.5)$ \\
\hline FVC (L) & $3.4(1.0)$ \\
\hline AWTPi10 $0^{a}$ & $3.7(0.1)$ \\
\hline \%LAA-950insp ${ }^{a}$ & $6.5(9.7)$ \\
\hline$\% L_{A A}-856 \exp { }^{a}$ & $21.6(19.5)$ \\
\hline$\% p L D A^{b}$ & $4.5(9.3)$ \\
\hline$\% f L D A^{b}$ & $19.5(14.2)$ \\
\hline
\end{tabular}

Data are expressed as mean (SD) or absolute numbers. AWTPi10 $=$ Average wall thickness of bronchi with an internal perimeter of $10 \mathrm{~mm}, B M I=$ Body mass index, $F E F=$ Forced expiratory flow, $F E V_{1} \%=$ forced expiratory volume in $1 \mathrm{sec}, \% \mathrm{fLDA}=$ percentage of functional low density area, $F V C=$ Forced vital capacity, GOLD = Global initiative for chronic Obstructive Lung Disease; $\% \mathrm{LAA}_{-950 i n s p}=$ percentage of lung attenuation area with values $<-950$ Hounsfield Units at inspiratory CT scan, \%LAA ${ }_{-856 e x p}=$ percentage of lung attenuation area with values $<-856$ Hounsfield Units at expiratory CT scan, $P E F=$ Peak expiratory flow, \% pLDA = percentage of persistent low density area, \%pred = percentage of predicted, $P R I S m=$ Preserved Ratio Impaired Spirometry, i.e. $\mathrm{FEV}_{1} / \mathrm{FVC} \geq 0.7$ and post-bronchodilator $\mathrm{FEV}_{1}<80 \%$ of predicted; ${ }^{a}$ parameters calculated by using VIDA software; ${ }^{b}$ parameters calculated by using Imbio software 
Table 2 Pearson's r correlations and determination coefficients $\left(R^{2}\right)$ between continuous $C T$ metrics of emphysema (\%LAA_950insp and \%pLDA) or airway disease (\% fLDA and AWTPi10) and functional parameters

\begin{tabular}{|c|c|c|c|c|c|c|c|c|c|}
\hline & \multicolumn{3}{|l|}{ ESI } & \multicolumn{3}{|l|}{$\mathrm{FEV}_{1}$} & \multicolumn{3}{|c|}{$\mathrm{FEV}_{1} / \mathrm{FVC}$} \\
\hline & $r$ & $R^{2}$ & $p$ & $r$ & $n$ & $p$ & $r$ & $R^{2}$ & $p$ \\
\hline \%LAA-950insp ${ }^{a}$ & 0.80 & 0.64 & $<.001$ & -0.60 & 0.36 & $<.001$ & -0.75 & 0.56 & $<.001$ \\
\hline$\% p L D A^{b}$ & 0.82 & 0.67 & $<.001$ & -0.63 & 0.40 & $<.001$ & -0.74 & 0.55 & $<.001$ \\
\hline$\% f L D A^{b}$ & 0.59 & 0.35 & $<.001$ & -0.58 & 0.34 & $<.001$ & -0.71 & 0.50 & $<.001$ \\
\hline WTPi10 ${ }^{a}$ & 0.17 & 0.03 & $<.001$ & -0.34 & 0.12 & $<.001$ & -0.16 & 0.03 & $<.001$ \\
\hline
\end{tabular}

Legend: $A W T P i 10=$ Average wall thickness of bronchi with an internal perimeter of $10 \mathrm{~mm}, \% \mathrm{fLDA}=$ percentage of functional low density area, $\% \mathrm{LAA}_{-950 i n s p}=$ percentage of lung attenuation area with values $<-950$ Hounsfield Units at inspiratory CT scan, \%pLDA = percentage of persistent low density area, ${ }^{a}$ parameters calculated by using Apollo (VIDA), ${ }^{b}$ parameters calculated by using Imbio

\%fLDA variability while explaining roughly the double (67\%) of that of \%pLDA. At variance with ESI, both $\mathrm{FEV}_{1}$ and $\mathrm{FEV}_{1} / \mathrm{FVC}$ had similar $\mathrm{R}^{2}$ values for emphysema and airway disease CT metrics. Multiple regression analysis demonstrated that the coefficient of determination $\mathrm{R}^{2}$ had only a small increase (from 0.67 to 0.71 ) of predictive ability when adding \%fLDA to the univariate correlation of ESI with \%pLDA. This indicates the specificity of ESI in detecting the emphysematous component of whole airway obstruction.

Table 3 shows differences in ESI values across GOLD stages and emphysema severity groups. All GOLD groups differed significantly for ESI mean values (Welch's $t$ - test $p<0.001$ ), increasing in parallel with GOLD stage with high variability within each stage. ESI mean values of both PRISm and GOLD 0 groups (0.9) were lower than those of GOLD 1-4 groups. Likewise, all CT emphysema severity groups differed significantly for ESI mean values (Welch's $t$-test $\mathrm{p}<0.001$ ).

Figure 1 shows the color-coded distribution of ESI values (0-10) in a graph comparing functional gas trapping (\%fLDA, non-emphysematous gas trapping) with total gas trapping (emphysematous and nonemphysematous, as derived from the relative lung area with CT attenuation below $-856 \mathrm{HU}$ at expiration). Most ESI values compatible with lower degrees of emphysema were located around the identity line between the two variables. Below $25-30 \%$ of total expiratory gas trapping there were only few data points compatible with significant emphysema, indicating that total gas trapping below that level was apparently due only to functional gas trapping. ESI values compatible with greater levels of emphysema were mostly located above $30 \%$ of total gas trapping and progressively dispersed above the identity line with the increase in total gas trapping.

Figure 2 shows the distribution and the numerical details of the three CT subgroups (NE, ME, SE) among the ranges of ESI values. The Goodman and Kruskal's gamma for the corresponding contingency table was $\mathrm{G}=0.82, p<0.001$. Ninety-two percent of subjects with $\mathrm{ESI} \leq 1$ were classified at $\mathrm{CT}$ as $\mathrm{NE}, 7.3 \%$ as $\mathrm{ME}$ and $0.4 \%$ as SE group. On the other side, $94.1 \%$ of subjects with ESI $\geq 9$ values were classified at $\mathrm{CT}$ as $\mathrm{SE}, 5.3 \%$ as $\mathrm{ME}$ and $0.5 \%$ as NE. Furthermore, with the progressive increase of ESI values there was a gradual increase in the percentage of subjects classified as SE and a gradual reduction in the percentage of subjects classified as NE. For those classified at CT as ME we observed an increase of the percentage of cases from ESI 0 to 2-3, then a slight trend to reduction.

\section{Discussion}

We have demonstrated the utility of ESI in identifying emphysema in a large and genetically diverse population of current and former smokers. ESI when combined with standard spirometric variables could help in discriminating the prevalent mechanism (i.e. emphysema or airway disease) underlying airflow obstruction. The method relies on each patient's MEFV curve morphology as

Table 3 Analysis of variance for ESI values among PRISm and GOLD stages and for subgroups with different emphysema severity (\%LAA-950insp) at CT

\begin{tabular}{|c|c|c|c|c|}
\hline & & $\mathrm{N}$ & ESI mean (SD) & $\begin{array}{l}\text { ANOVA / } \\
\text { Welch's } \boldsymbol{t} \text {-test }\end{array}$ \\
\hline \multirow[t]{6}{*}{ PRISm and GOLD stages } & PRISm & 641 & $0.9(0.4)$ & \multirow[t]{6}{*}{$p<.001$} \\
\hline & 0 & 2646 & $0.9(0.3)$ & \\
\hline & 1 & 499 & $1.4(0.4)$ & \\
\hline & 2 & 1169 & $2.1(1.1)$ & \\
\hline & 3 & 662 & $5.0(2.1)$ & \\
\hline & 4 & 313 & $8.3(2.0)$ & \\
\hline \multirow[t]{3}{*}{ \%LAA-950insp } & No Emphysema (<6\%) & 4223 & $1.1(0.8)$ & \multirow[t]{3}{*}{$p<.001$} \\
\hline & Moderate Emphysema (6-14\%) & 866 & $2.4(2.0)$ & \\
\hline & Severe Emphysema ( $\geq 14 \%)$ & 841 & $5.9(2.8)$ & \\
\hline
\end{tabular}




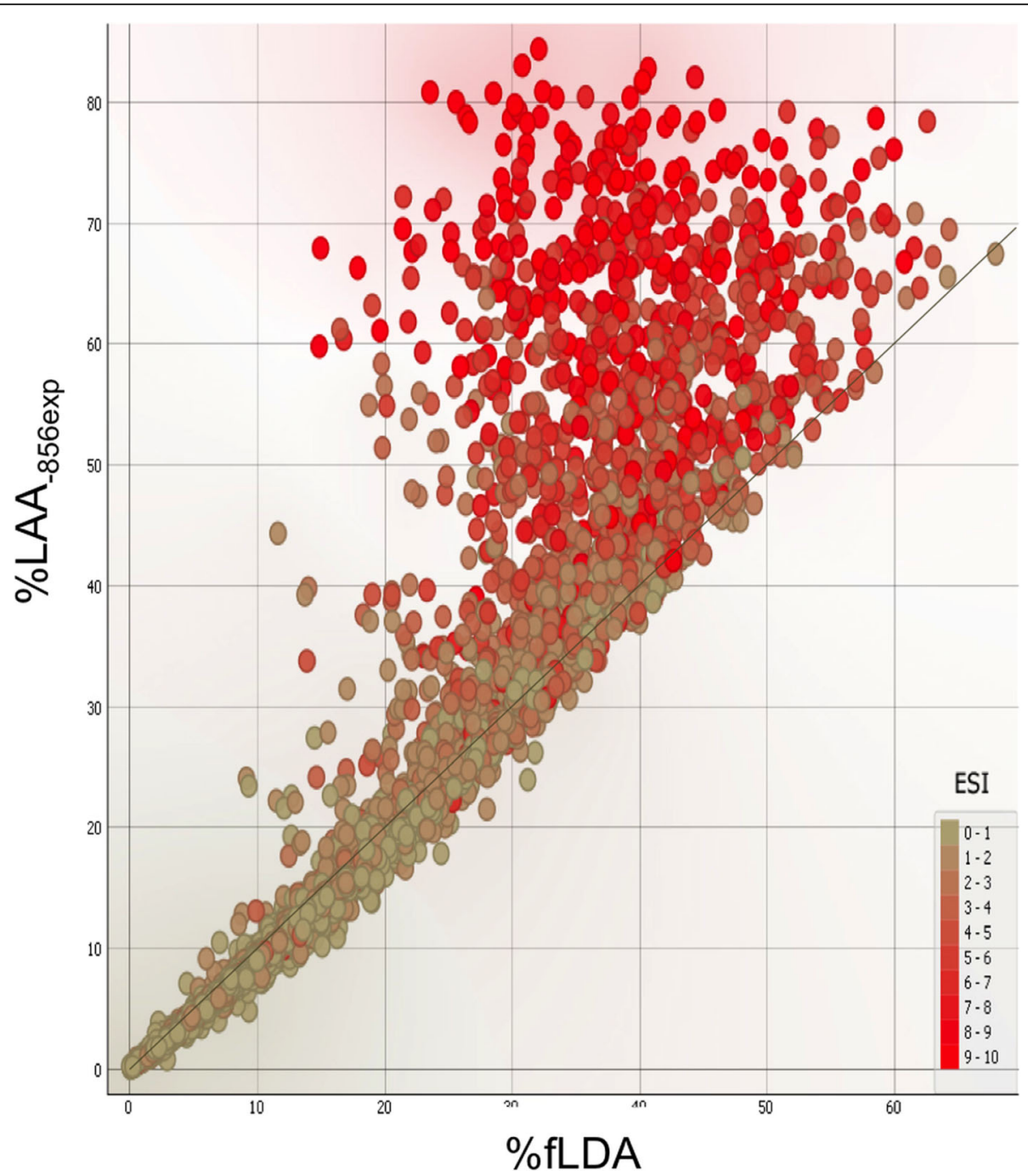

Fig. 1 Distribution of the COPDGene population according to $C T$ derived metrics: total expiratory gas trapping (y-axis, \%LAA-856exp) and functional gas trapping ( $x$-axis, \%fLDA). Data points are colored according to the corresponding ESI values calculated by spirometry (progressive range $0-10$ ). Total expiratory gas trapping entails the air trapped in the lungs at the end of a forced expiration due to both conductive airway disease (functional gas trapping, \%fLDA) and emphysematous parenchymal destruction, whose amount is represented by the ESI values

derived from absolute values of discrete spirometric variables, thus being independent of percent-predicted values.

The forced expiratory maneuver is the basic lung function test used to detect airflow obstruction [24]. In the late '70s, Saltzman [25] proposed that a "kinking" of the descending limb of the MEFV curve might represent a sign of airway collapse reflecting the presence of emphysema. In the following decades some papers have considered the study of the MEFV curve morphology as a possible method to distinguish normal aging from less paraphysiological airflow obstruction [26] or to predict emphysema [27-29] or chronic bronchitis [30] by spirometry. All studies investigated either the kinking in different portions of the MEFV curve descending limb or its continuous flow-decay
(30) using mathematical linear models to approach the curvilinear shape of the MEFV curve.

The shape of the MEFV curve has also been studied to assess whether it could identify mild airflow obstruction in subjects with otherwise normal spirometry $[31,32]$. A recent study has shown that the area under the MEFV curve could provide a superior estimation of severe hyperinflation than conventional indices like RV/TLC and IC/TLC in patients with COPD [33]. However, these studies did not differentiate the contribution of emphysema or small airway disease to airflow obstruction. In a previous pilot study, in a small population of patients with COPD, it has been demonstrated that presence and severity of emphysema as quantified by CT metrics and radiomics can be estimated by mathematical modeling of 


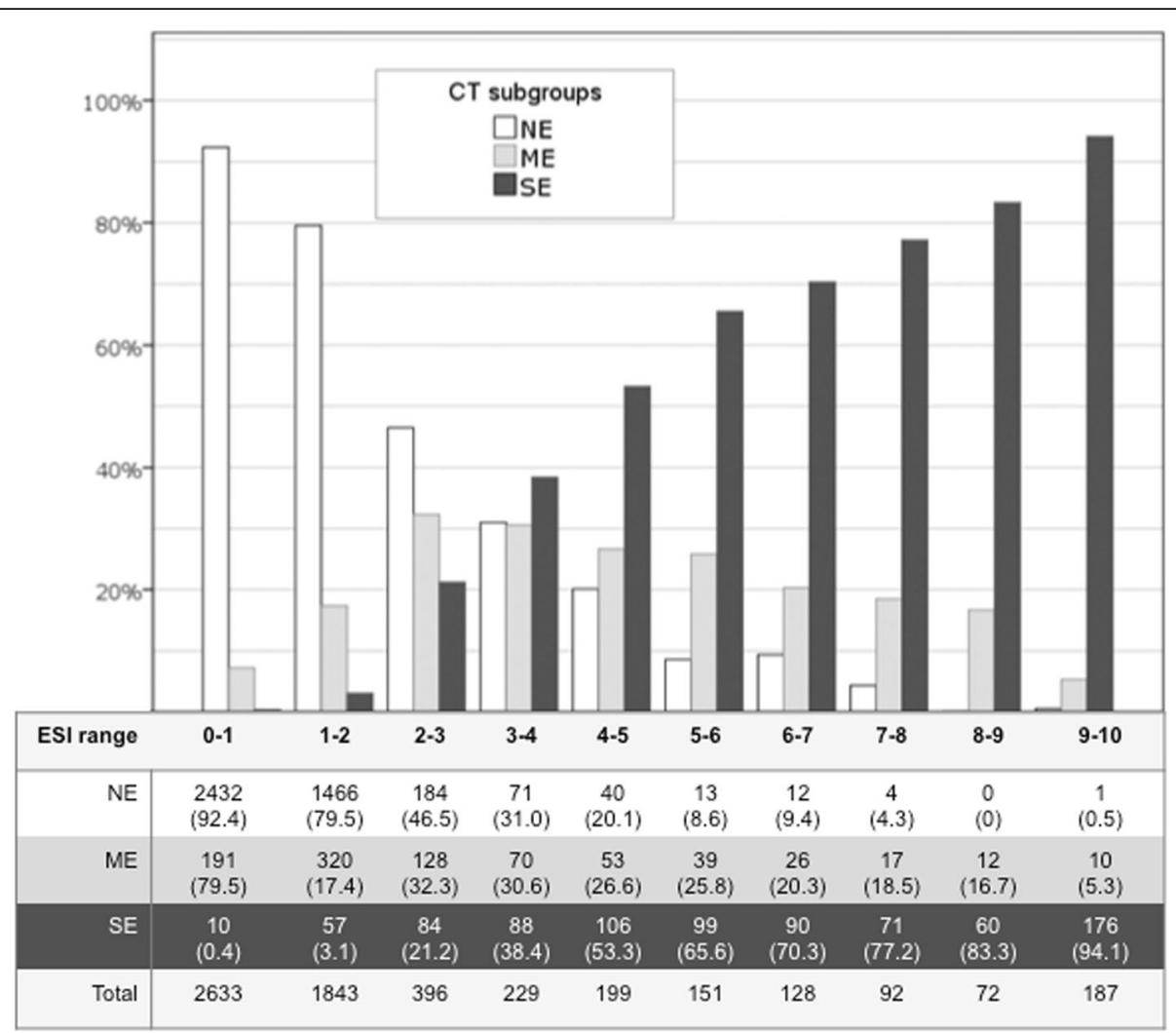

Fig. 2 Distribution of ESI values across the different emphysema subgroups as assessed by CT. White bars represent the percentages for NE (no emphysema, \%LAA_-950insp $<6$ ), light gray bars for ME (moderate emphysema, $6 \leq \%$ LAA_-950insp $<14$ ), and dark gray bars for SE (severe emphysema, \%LAA_-950insp $\geq 14$ ). Data in the table represent absolute numbers (percentages). The Goodman and Kruskal's Gamma for the corresponding contingency table is $\mathrm{G}=0.82, p<0.001$

airway function as derived from standard spirometry [18]. Here we confirm in a larger population, including smokers with normal lung function at standard spirometry, that the analysis of MEFV curve descending limb can generate a functional index (ESI) that is more strongly correlated than standard functional parameters with CT metrics indicative of emphysema and to a considerably lesser extent with CT metrics indicating airway disease. At variance with ESI the correlation with emphysema or airway disease CT metrics of standard functional parameters did not significantly differ. These results support the ability of ESI to specifically capture the emphysematous contribution to airflow obstruction. The finding of similar ESI values in PRISm and GOLD 0 groups further support the specificity of ESI in detecting the presence of emphysema. Thus, ESI could complement the assessment of airflow obstruction at spirometry to differentiate patients with similar degrees of airflow obstruction but different degrees of emphysema severity.

Analysis of ESI values across CT subgroups of emphysema severity showed either a significant progressive reduction or increase in ESI values in NE and SE subgroups, respectively. Conversely, ESI values in ME subgroup showed less consistency throughout the CT subgroups. This could possibly be explained by the fact that \%LAA_-950insp only represents extent of parenchymal destruction as reflected by X-ray attenuation and not an index of specific morphologic features in terms of emphysema subtypes. ME subgroup may then include subjects with mild emphysema, centrilobular or paraseptal. Centrilobular and paraseptal emphysema less than 6\% extent on CT can be present also in NE patients (7). This may cause some data dispersion in the correlation between ESI and CT data. In fact, for the same level of \%LAA_950insp, centrilobular emphysema would affect the MEFV curve morphology to a greater extent than paraseptal emphysema, which is located in the more peripheral regions of the lung. A relationship between the qualitative CT features of the COPD subtypes observed in the COPDGene population [34] and the corresponding ESI values has not been performed yet. The study of this relationship, which is out of the scope of this paper, could be essential to confirm the speculations above.

The distribution of the large COPDGene population according to total and functional gas trapping (Fig. 1) is 
in line with the previous observation that subjects with an amount of total gas trapping around or below 30\% have negligible amounts of emphysema [12]. This suggests that gas trapping in these subjects derives mostly from the non-emphysematous component, in line with recent data showing that terminal bronchioles are narrowed and destroyed before the onset of emphysematous changes [35]. If total gas trapping is around or above $30 \%$ the emphysema component adds to the nonemphysematous one, resulting in progressive data dispersion above the identity line. We hypothesize that the severity of emphysema is proportional to the distance from the identity line that relates total gas trapping with functional gas trapping. A longitudinal analysis of COPD progression could ascertain whether the spectrum of the disorder as observed in this study reflects different degrees of severity of the same disease or just different disease entities sharing airflow obstruction at spirometry.

Our study has several strengths. We analyzed a large multiethnic population of smokers who underwent extensive phenotyping with spirometry and CT imaging. Unlike previous studies [27, 28] we compared our results with CT metrics deemed to reflect both emphysema and airways disease. Our method is not a probabilistic predictive model trained on a specific learning set, but it depends only on the specific shape of each MEFV curve. An important step forward is the development of an application for real-time analysis, making ESI suitable for routine clinical use, for application on prospective widescale clinical trials, and for application in post-hoc analyses of previous randomized pharmacologic clinical trials to evaluate the effects of emphysema severity on the outcome.

Our study has also limitations. First, the method relies on a well-performed MEFV curve. The automated quality check performed by ESI excluded only 71 patients in whom spirometric data acquisition was closely controlled. The number of patients excluded from the calculation of ESI could be higher in less controlled studies. Second, we were unable to compare our score with the severity of emphysema as assessed by absolute lung volumes and diffusing capacity for carbon monoxide, as these data as well as the measurement of slow vital capacity (VC), were not available in the COPDGene study at baseline. However, in a previous study ESI was strongly correlated with absolute lung volumes and diffusing capacity [18]. Third, we compared ESI with CT metrics that reflect overall parenchymal destruction at predefined attenuation thresholds as surrogate of emphysema. However, the thresholds considered are those generally used in studies comparing CT data with other measurements. Fourth, expiratory CT scans were acquired at end-tidal expiration and not at end-forced expiration that correspond to the end of the expiratory effort at spirometry. However, this difference in lung volumes at expiration could have only reduced our validation performances by CT.

\section{Conclusions}

This study shows that the analysis of the MEFV curve downslope can provide an index of emphysema presence and severity (ESI), independent of percent-predicted values, validated on CT scans and in the large multiethnic population of smokers of the COPDGene study. Therefore, ESI can be applied for clinical and research purposes in the general population of smokers to add to standard spirometry the power to discriminate whether emphysema or airways disease is the predominant mechanism of airway obstruction.

\section{Abbreviations}

AWTPi10: Average wall thickness of medium-sized airways with internal perimeter of $10 \mathrm{~mm}$; COPD: Chronic obstructive pulmonary disease; CT: Computed tomography; ESI: Emphysema severity index; FEF: Forced expiratory flow; FEV 1 : Forced expiratory volume in $1 \mathrm{~s} ; \%$ fLDA: Percent of functional low-density area; FVC: Forced vital capacity; VC: Vital capacity; GOLD: Global initiative for chronic Obstructive Lung Disease; HU: Hounsfield Units; \%LAA_-950ins: Percent lung attenuation area below

-950HU at inspiratory CT; MEFV: Maximal expiratory flow-volume; NE: No emphysema; ME: Moderate emphysema; PEF: Peak expiratory flow; \%pLDA: Percent of persistent low-density area; PRISm: Preserved Ratio Impaired Spirometry; SE: Severe emphysema

\section{Aknowledgements}

We are deeply indebted to Carla Wilson for her kind help in the database management.

\section{Authors' contributions}

Study concepts/study design or data acquisition or data analysis/ interpretation: MO, MPa, JDC, DAL, VB, EKS, EAR, MPi. Manuscript drafting or manuscript revision for important intellectual content: all authors. Manuscript final version approval: all authors. Literature research: $M O, M P a, F L, V B, M P i$. Clinical studies: JDC, BJM, DAL, EKS, EAR. Data analysis: MO, MPa, EAR, MPi. Manuscript editing: all authors. All authors read and approved the final version of the manuscript.

\section{Funding}

Grant Support and Disclaimer

The project described was supported by Award Number U01 HL089897 and Award Number U01 HL089856 from the National Heart, Lung, and Blood Institute. The content is solely the responsibility of the authors and does not necessarily represent the official views of the National Heart, Lung, and Blood Institute or the National Institutes of Health.

COPD Foundation Funding

The COPDGene ${ }^{\circledast}$ project is also supported by the COPD Foundation through contributions made to an Industry Advisory Board comprised of AstraZeneca, Boehringer Ingelheim, GlaxoSmithKline, Novartis, Pfizer, Siemens and

Sunovion.

They had no role in study design and collection, analysis, interpretation of data, and in writing the manuscript.

\section{Availability of data and materials}

Individual participant data that underlie the results reported in this article, after de-identification (text, tables, figures, and appendices) will be available together with the study protocol beginning 9 months and ending 12 months following article publication. Data will be available with investigators whose proposed use of the data has been approved by an independent review committee ("learned intermediary") identified for this purpose. Proposals may be submitted up to 12 months following article publication. After 12 months the data will be available in our university's data warehouse but without investigator support other than deposited metadata. 


\section{Ethics approval and consent to participate}

Institutional review boards approved the COPDGene Study across the 21 US participating Clinical Centers between January 2008 and June 2011. All participants provided written informed consent.

\section{Consent for publication}

Not applicable.

\section{Competing interests}

Dr. Occhipinti reports grants from Menarini Foundation, during the conduct of the study.

Dr. Crapo reports grants from $\mathrm{NIH} / \mathrm{NHLBl}$, during the conduct of the study. Dr. Make reports funding from the NHLBI for the COPDGene study; grants and medical advisory boards from Boehringer Ingelheim, GlaxoSmithKline, AstraZeneca, and Sunovian; personal fees for DSMB from Spiration and Shire/ Baxalta; CME personal fees from WebMD, National Jewish Health, American College of Chest Physicians, Projects in Knowledge, Hybrid Communications, SPIRE Learning, Ultimate Medical Academy, Catamount Medical, Eastern Pulmonary Society, Catamount Medical Communications Medscape, Eastern VA Medical Center, Academy Continued Healthcare Learning, and Mt. Sinai Medical Center; royalites from Up-To-Date; medical advisory boards from Novartis, Phillips, Third Pole, Science 24/7, and Vernoa; grants from Pearl; outside the submitted work.

Dr. Lynch reports grants from NHLBI, personal fees from Parexel, personal fees from Veracyte, personal fees from Boehringer Ingelheim, personal fees from Genentech/Roche, from Acceleron, outside the submitted work; In addition, Dr. Lynch has a patent SYSTEMS AND METHODS FOR CLASSIFYING SEVERITY OF COPD pending.

Dr. Silverman reports grants from $\mathrm{NIH}$, during the conduct of the study: grants and other from GlaxoSmithKline, outside the submitted work. Dr. Pistolesi reports grants and personal fees from Menarini, personal fees from MSD, personal fees from Boehringer Ingelheim, personal fees from Novartis, personal fees from Zambon, personal fees from Grifols, personal fees from Menarini International, personal fees from Guidotti-Malesci, personal fees from CS Bering, non-financial support from VIDA Diagnostics, outside the submitted work.

\section{Author details}

'Section of Respiratory Medicine, Department of Experimental and Clinical Medicine, University of Florence, Largo A. Brambilla 3, 50134 Florence, Italy. ${ }^{2}$ Section of Radiology, Department of Biomedical, Experimental, and Clinical Sciences, University of Florence, Largo A. Brambilla 3, 50134 Florence, Italy. ${ }^{3}$ Department of Medicine, National Jewish Health, 1400 Jackson St, Denver CO 80206, USA. ${ }^{4}$ Department of Radiology, National Jewish Health, 1400 Jackson St, Denver CO 80206, USA. ${ }^{5}$ Department of Experimental Medicine, University of Genoa, Via Leon Battista Alberti 2, 16132 Genoa, Italy. ${ }^{6}$ Department of Medicine, Harvard Medical School, Brigham and Women's Hospital, Channing Division of Network Medicine, 75 Francis St, Boston MA 02115, USA.

\section{Received: 26 February 2020 Accepted: 20 April 2020} Published online: 01 May 2020

\section{References}

1. Burrows B, Fletcher CM, Heard BE, Jones NL, Wootliff JS. The emphysematous and bronchial types of chronic airways obstruction. A clinicopathological study of patients in London and Chicago. Lancet. 1966;1: 830-5.

2. Camiciottoli G, Bigazzi F, Paoletti M, Cestelli L, Lavorini F, Pistolesi M. Pulmonary function and sputum characteristics predict computed tomography phenotype and severity of COPD. Eur Respir J. 2013;42:626-35.

3. Lange P, Celli B, Agusti A. Lung-function trajectories and chronic obstructive pulmonary disease. N Engl J Med. 2015;373:1575.

4. Burgel PR, Paillasseur JL, Janssens W, Piquet J, Ter Riet G, Garcia-Aymerich J, et al. A simple algorithm for the identification of clinical COPD phenotypes. Eur Respir J. 2017;50. https://doi.org/10.1183/13993003.01034-2017.

5. Nishimura M, Makita H, Nagai K, Konno S, Nasuhara Y, Hasegawa M, et al. Annual change in pulmonary function and clinical phenotype in chronic obstructive pulmonary disease. Am J Respir Crit Care Med. 2012;185:44-52.
6. Johannessen A, Skorge TD, Bottai M, Grydeland TB, Nilsen RM, Coxson H, et al. Mortality by level of emphysema and airway wall thickness. Am J Respir Crit Care Med. 2013;187:602-8.

7. Lynch DA, Austin JH, Hogg JC, Grenier PA, Kauczor HU, Bankier AA, et al. CT-definable subtypes of chronic obstructive pulmonary disease: a statement of the Fleischner society. Radiology. 2015;277:192-205.

8. Hogg JC, Pare PD, Hackett TL. The contribution of small airway obstruction to the pathogenesis of chronic obstructive pulmonary disease. Physiol Rev. 2017:97:529-52.

9. Madani A, De Maertelaer V, Zanen J, Gevenois PA. Pulmonary emphysema: radiation dose and section thickness at multidetector $C T$ quantification-comparison with macroscopic and microscopic morphometry. Radiology. 2007;243:250-7.

10. Hackx M, Bankier AA, Gevenois PA. Chronic obstructive pulmonary disease: CT quantification of airways disease. Radiology. 2012;265:34-48.

11. Paoletti M, Cestelli L, Bigazzi F, Camiciottoli G, Pistolesi M. Chronic obstructive pulmonary disease: pulmonary function and CT lung attenuation do not show linear correlation. Radiology. 2015;276:571-8.

12. Occhipinti M, Paoletti M, Bigazzi F, Camiciottoli G, Inchingolo R, Larici AR, et al. Emphysematous and nonemphysematous gas trapping in chronic obstructive pulmonary disease: quantitative $C T$ findings and pulmonary function. Radiology. 2018;287:683-92.

13. Galban CJ, Han MK, Boes JL, Chughtai KA, Meyer CR, Johnson TD, et al. Computed tomography-based biomarker provides unique signature for diagnosis of COPD phenotypes and disease progression. Nat Med. 2012;18:1711-5.

14. Kirby M, Yin Y, Tschirren J, Tan WC, Leipsic J, Hague CJ, et al. A novel method of estimating small airway disease using inspiratory-to-expiratory computed tomography. Respiration. 2017;94:336-45.

15. Vestbo J, Anderson W, Coxson HO, Crim C, Dawber F, Edwards L, et al. Evaluation of COPD longitudinally to identify predictive surrogate endpoints (ECLIPSE). Eur Respir J. 2008;31:869-73.

16. Regan EA, Hokanson JE, Murphy JR, Make B, Lynch DA, Beaty TH, et al. Genetic epidemiology of COPD (COPDGene) study design. COPD. 2010;7:32-43.

17. Adeloye D, Chua S, Lee C, Basquill C, Papana A, Theodoratou E, et al. Global and regional estimates of COPD prevalence: systematic review and metaanalysis. J Glob Health. 2015;5:020415.

18. Occhipinti M, Paoletti M, Bartholmai BJ, Rajagoplan S, Karwoski RA, Nardi C, Inchingolo R, Larici AR, Camiciottoli G, Lavorini F, Colagrande S, Brusasco V, Pistolesi M. Spirometric assessment of emphysema presence and severity as measured by quantitative CT and CT-based radiomics in COPD. Respir Res. 2019;20:101.

19. Miller MR, Hankinson J, Brusasco V, Burgos F, Casaburi R, Coates A, et al. Standardisation of spirometry. Eur Respir J. 2005;26:319-38.

20. Schroeder JD, McKenzie AS, Zach JA, Wilson CG, Curran-Everett D, Stinson DS, et al. Relationships between airflow obstruction and quantitative CT measurements of emphysema, air trapping, and airways in subjects with and without chronic obstructive pulmonary disease. AJR Am J Roentgenol. 2013;201:W460-70.

21. Steiger $\mathrm{JH}$. Tests for comparing elements of a correlation matrix. Psychol Bull. 1980;87:245-51.

22. Hersh CP, Washko GR, Estepar RS, Lutz S, Friedman PJ, Han MK, et al. Paired inspiratory-expiratory chest $C T$ scans to assess for small airways disease in COPD. Respir Res. 2013;14:42.

23. Stajdohar M, Demsar J. Interactive network exploration with Orange. J Stat Softw. 2013;53:1-24.

24. Pellegrino R, Viegi G, Brusasco V, Crapo RO, Burgos F, Casaburi R, et al. Interpretative strategies for lung function tests. Eur Respir J. 2005;26:948-68.

25. Saltzman HP, Ciulla EM, Kuperman AS. The spirographic "kink". A sign of emphysema. Chest. 1976;69:51-5.

26. Mead J. Analysis of the configuration of maximum expiratory flow-volume curves. J Appl Physiol Respir Environ Exerc Physiol. 1978;44:156-65.

27. Topalovic M, Exadaktylos V, Peeters A, Coolen J, Dewever W, Hemeryck M, et al. Computer quantification of airway collapse on forced expiration to predict the presence of emphysema. Respir Res. 2013;14:131.

28. Wang W, Xie M, Dou S, Cui L, Xiao W. Computer quantification of "angle of collapse" on maximum expiratory flow volume curve for diagnosing asthma-COPD overlap syndrome. Int J Chron Obstruct Pulmon Dis. 2016;11: 3015-22.

29. O'Donnell CR, Rose RM. The flow-ratio index. An approach for measuring the influence of age and cigarette smoking on maximum expiratory flowvolume curve configuration. Chest. 1990;98:643-6. 
30. Kapp MC, Schachter EN, Beck GJ, Maunder LR, Witek TJ Jr. The shape of the maximum expiratory flow volume curve. Chest. 1988;94:799-806.

31. Dominelli PB, Foster GE, Guenette JA, Haverkamp HC, Eves ND, Dominelli GS, et al. Quantifying the shape of the maximal expiratory flow-volume curve in mild COPD. Respir Physiol Neurobiol. 2015;219:30-5.

32. Bhatt SP, Bhakta NR, Wilson CG, Cooper CB, Barjaktarevic I, Bodduluri S, et al. New spirometry indices for detecting mild airflow obstruction. Nature Sci Rep. 2018;8:17484.

33. Das N, Topalovic M, Aerts JM, Janssens W. Area under the forced expiratory flow-volume loop in spirometry indicates severe hyperinflation in COPD patients. Int J Chron Obstruct Pulmon Dis. 2019;14:409-18.

34. Lynch DA, Moore CM, Wilson C, Nevrekar D, Jennermann T, Humphries SM, et al. CT-based visual classification of emphysema: association with mortality in the COPDGene study. Radiology. 2018;288:859-66.

35. McDonough JE, Yuan R, Suzuki M, Seyednejad N, Elliott WM, Sanchez PG, et al. Small-airway obstruction and emphysema in chronic obstructive pulmonary disease. N Engl J Med. 2011;365:1567-75.

\section{Publisher's Note}

Springer Nature remains neutral with regard to jurisdictional claims in published maps and institutional affiliations.

Ready to submit your research? Choose BMC and benefit from:

- fast, convenient online submission

- thorough peer review by experienced researchers in your field

- rapid publication on acceptance

- support for research data, including large and complex data types

- gold Open Access which fosters wider collaboration and increased citations

- maximum visibility for your research: over $100 \mathrm{M}$ website views per year

At BMC, research is always in progress.

Learn more biomedcentral.com/submissions 